\title{
هرمينوطيقا الذات عند بول ريكور
}

\author{
أ. هرنون نصيرة \\ المدرسة العليا للأستاذة قسم الفلسفة \\ قسنطينة
}

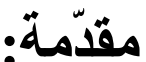

أكد بول ريكور أن الثقة التي كان يفتخر بها

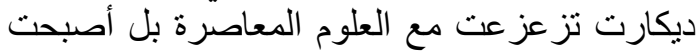

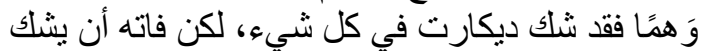

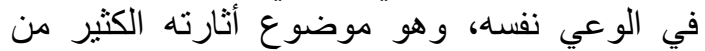

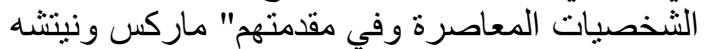

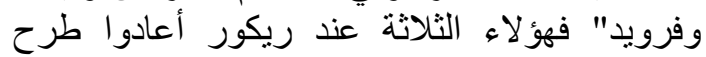

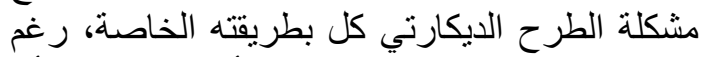

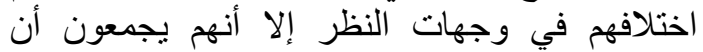

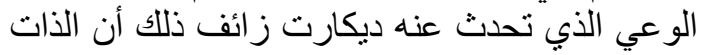
عند بول ريكور لم تعد متيقنة من إدر اكها لثفا لثفافيتها ولابد لأي فلسفة تأويلية من أن ترتبط بفلسفة تلفية تفكيرية

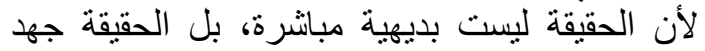
مستمر للخروج من الذات و الإقامة عند الآخر ، و عليه

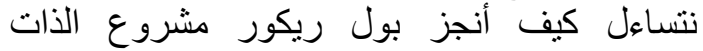
المتعددة ؟ وماهو المنهج الذي اعتمده لتحقيقه؟

$$
\begin{aligned}
& \text { بول ريكور من أبرز الثخصيات الفكرية التي عرفت إهتماما بالغا في الآونة }
\end{aligned}
$$

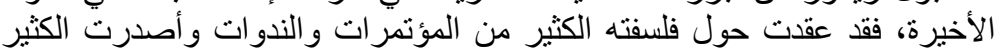

$$
\begin{aligned}
& \text { من الكتب ونشرت العديد من المقالات. }
\end{aligned}
$$

حيث عرف بمحاولته الجادة للمؤاخاة بين أنتروبولوجيا فلسفية تسعى التهى

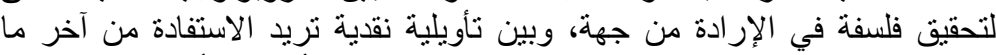

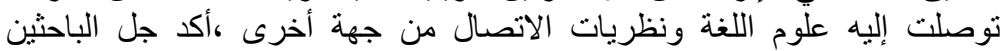

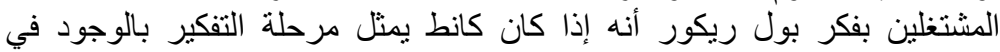

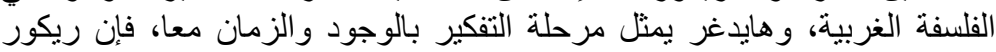

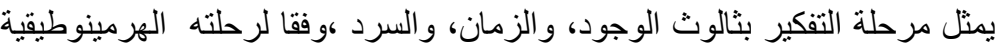

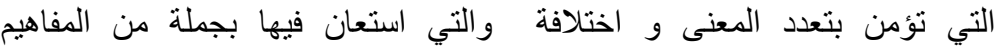

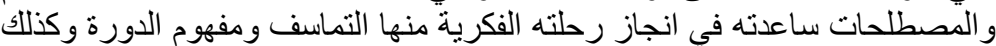

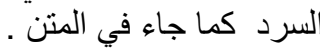

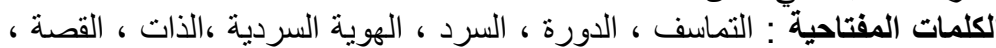

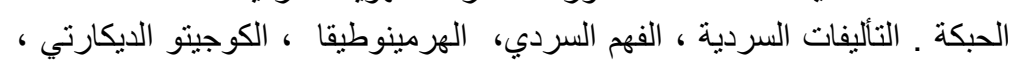
فلاسفة الارتياب

\section{Abstract:}

Paul Ricoeur is one of the most prominent intellectual figures of great interest. He has held many conferences and symposia around his philosophy, published many books and published many articles. Where he was known for his serious attempt of brotherhood between philosophical anthropology seeking to achieve aphilosophy at will, on the one hand, and a monetary interpretation that wants to take advantage of the latest in the science of language and theories of communication on the other hand, most researchers working with Paul Ricour thought that if Kant represents the stage of thinking of being in Western philosophy, and Heidegger represents the stage of thinking about both existence and time

Ricoeur represents the stage of thinking about the triad of existence, time, and narration, in accordance with his Hermetic journey, which believes in multiple meanings and convictions, in which he used a number of concepts and terms that helped him to complete his intellectual journey, including the quest and the concept of the cycle, as well as the narrative as stated in the text.

Keywords: defiance, cycle, narration, narrative identity, self, story, plot. Narrative correlations, narrative comprehension, Hermeneutics, Cartesian Kujito, philosophers of suspicion. 


\section{1. ضبط مفهوم التأويل الهرمينوطيقي عند بول ريكور:}

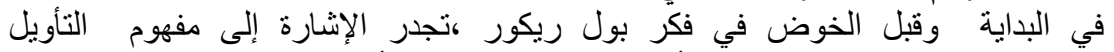

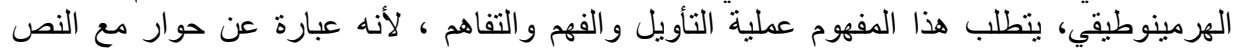

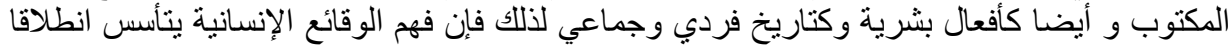

$$
\text { من النصوص المقرو أبطاء و المحكية (السرد). }
$$

إذن الفهم المرتبط بالتأويل هو عبارة عن حوار بار بين الذات والآخر نتيجة هذا الحوار تولد

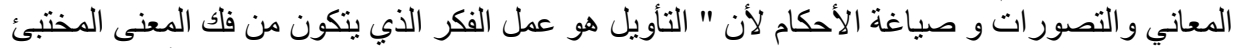

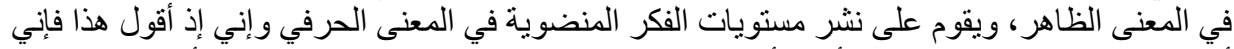

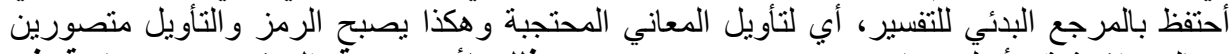

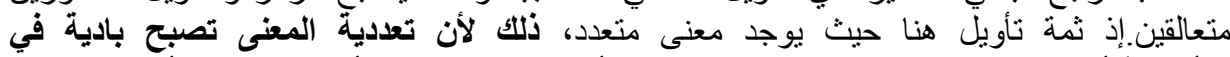

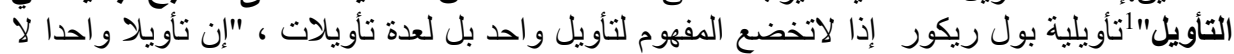

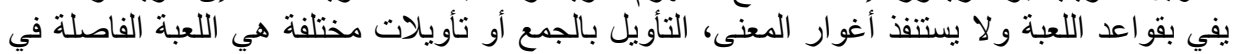

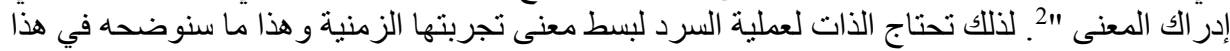

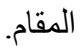

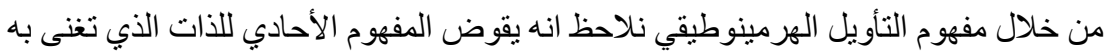

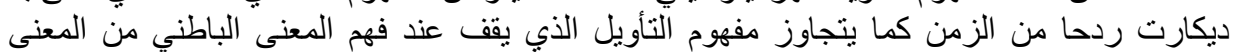

الخارجي كما هو الحال عند فلاسفة الارتياب .

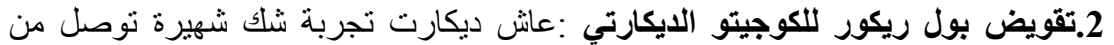

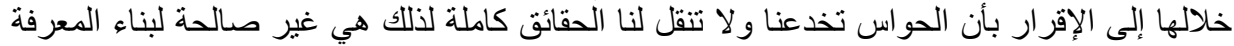

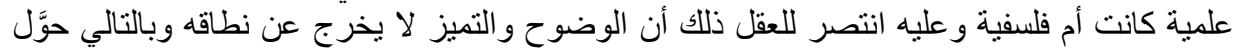

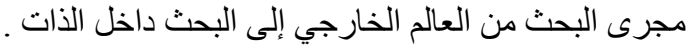

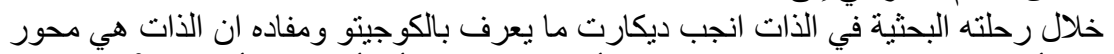

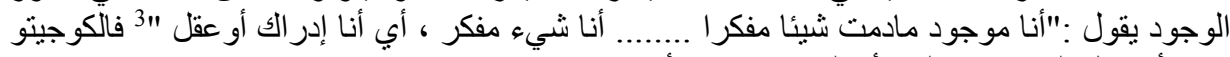

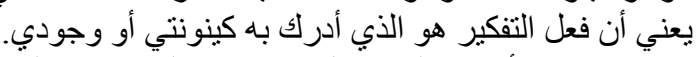

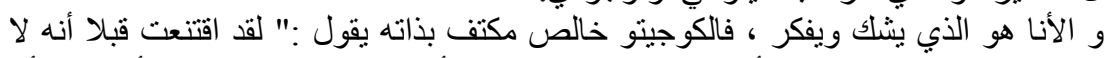

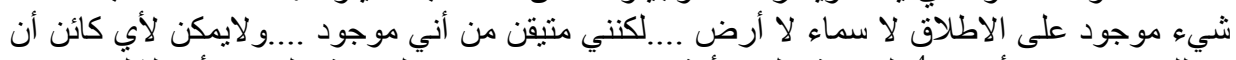

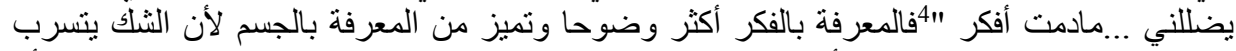

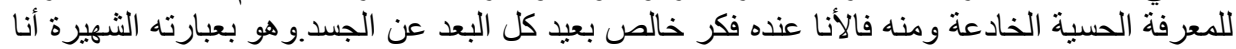

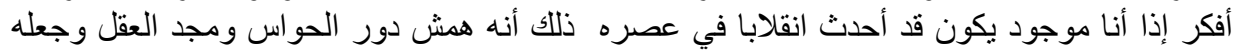

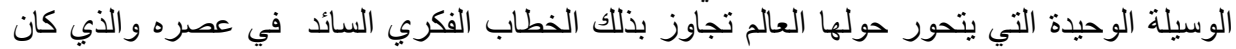

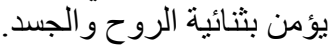

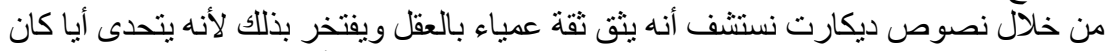

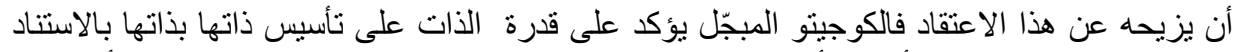

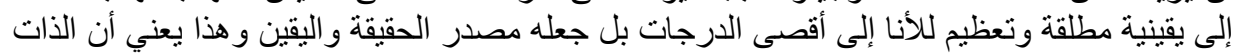

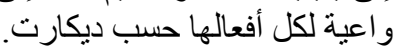

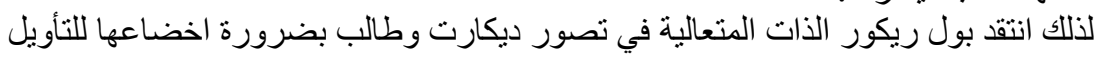

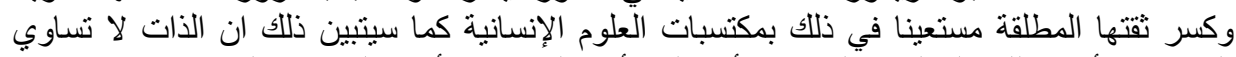

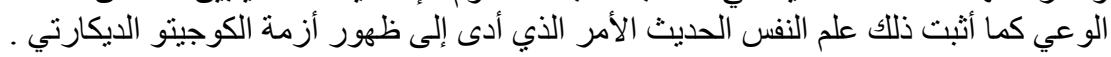

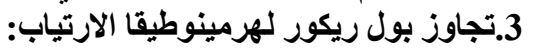




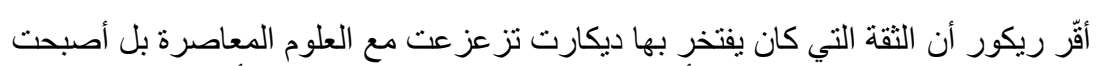

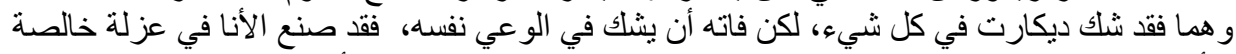

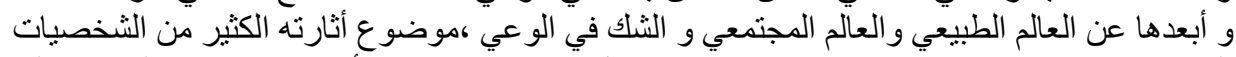

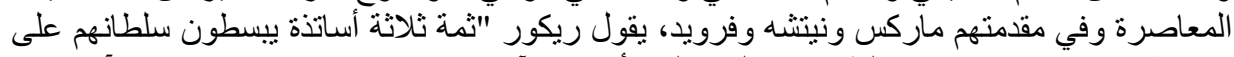

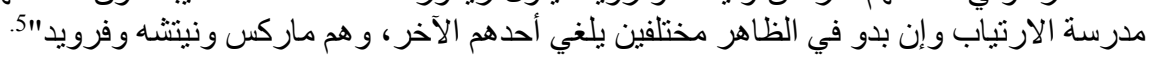

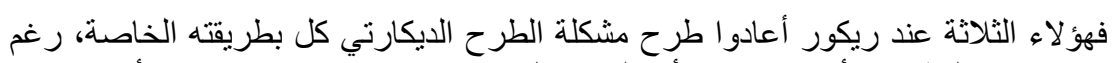

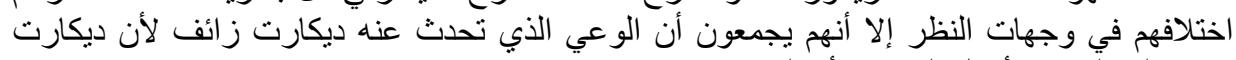

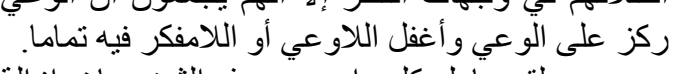

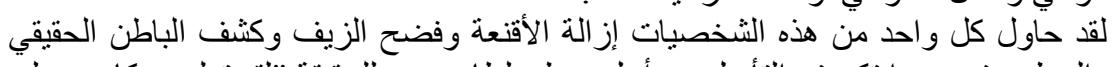

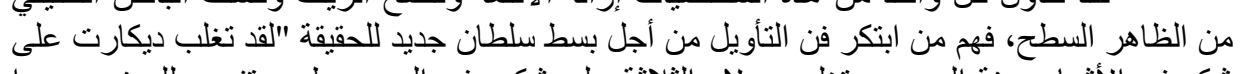

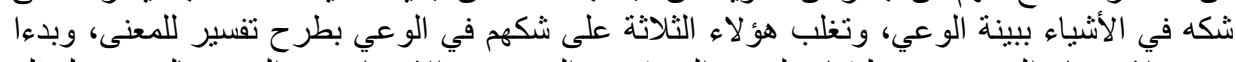

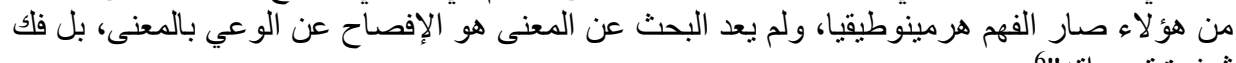

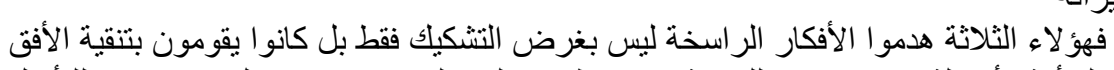
شيفرة تعبير اته" 6

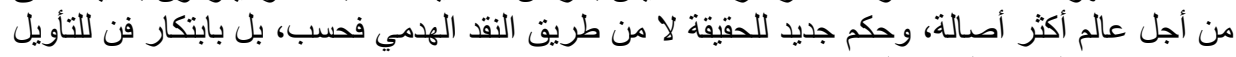

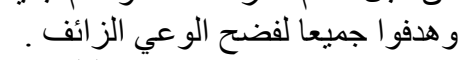

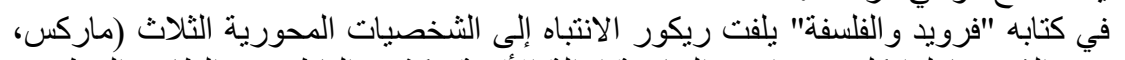

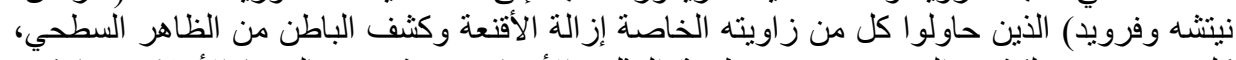

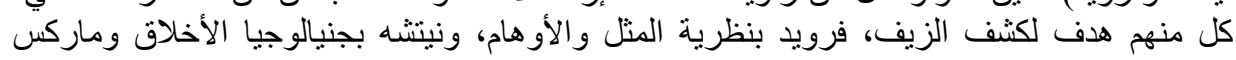

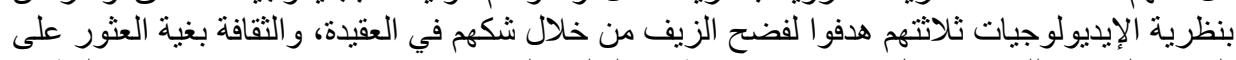

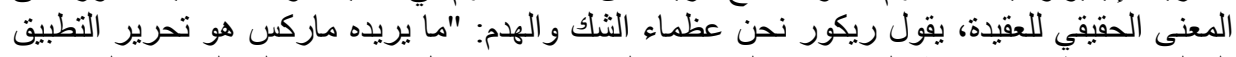

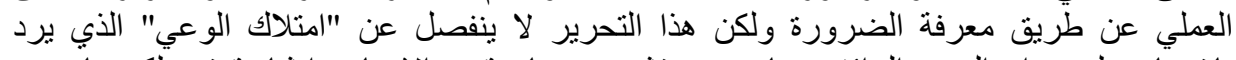

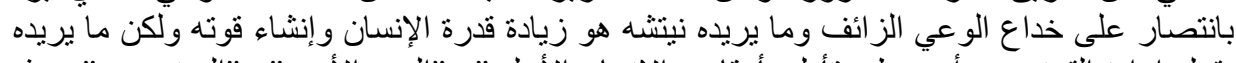

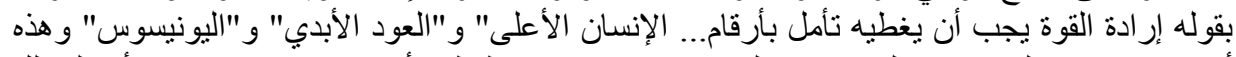

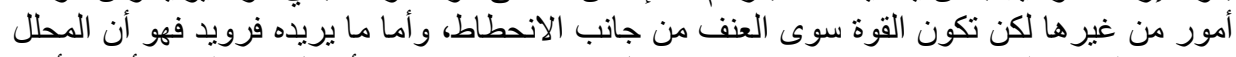

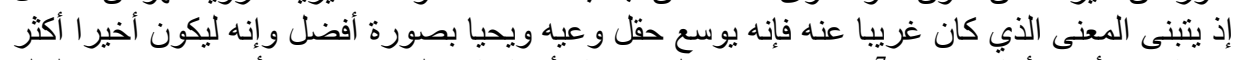

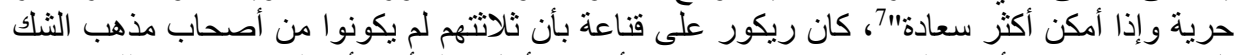

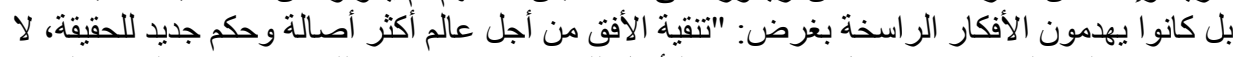

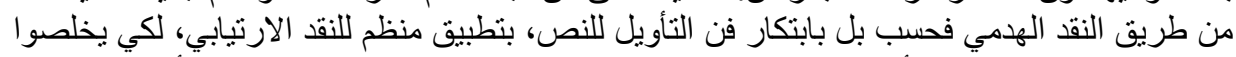

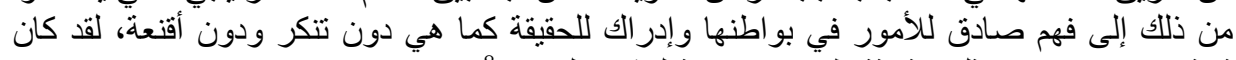

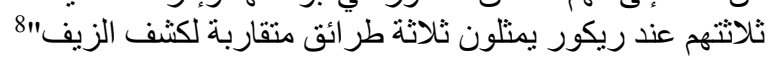

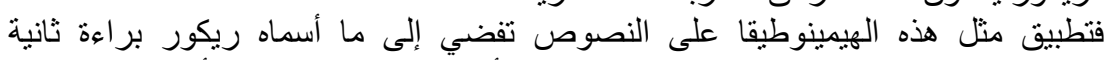
Second Naiscete

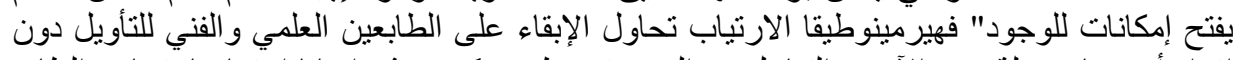

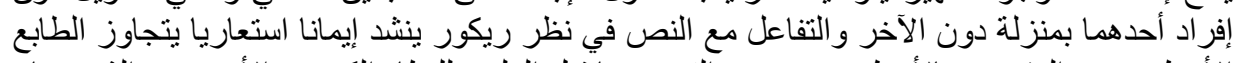

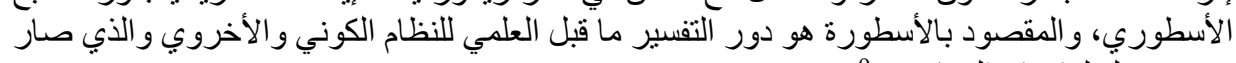

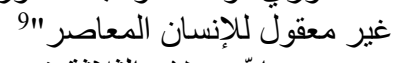

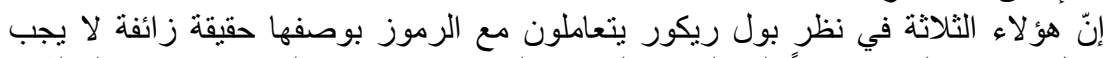

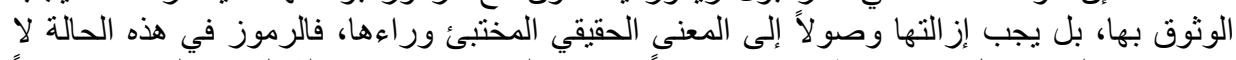

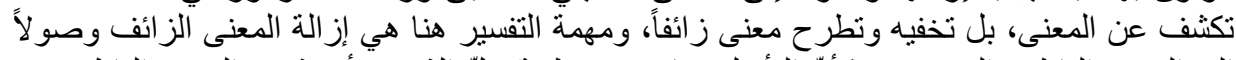

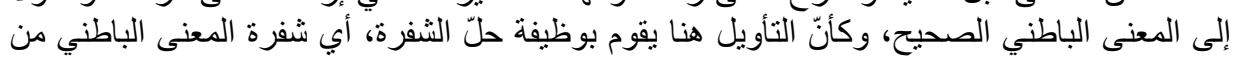




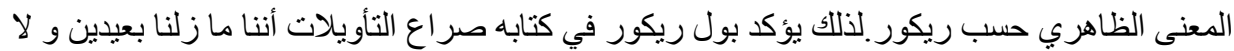

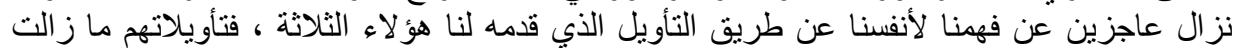

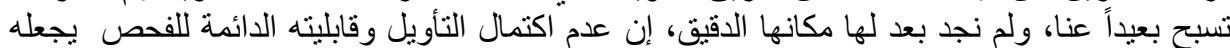
دوماً تأويلاً معلقاً .

\section{4.تطبيق هرمينوطيقا بول ريكور:}

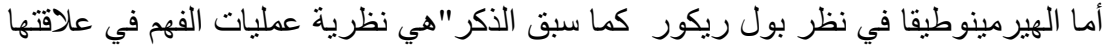

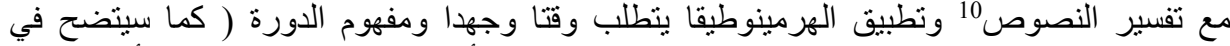

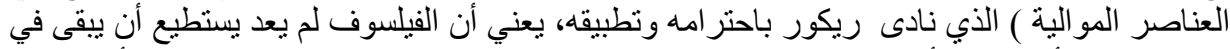

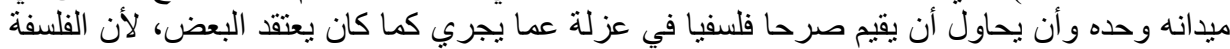

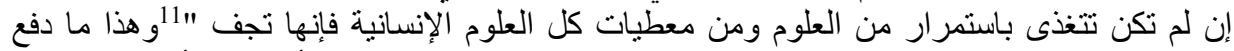

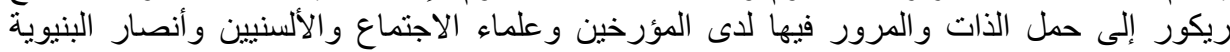

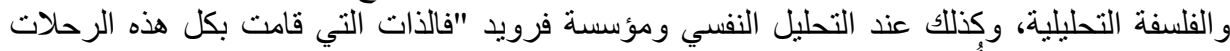

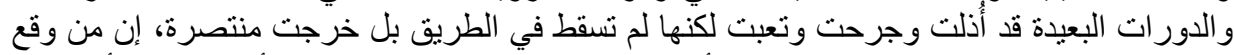

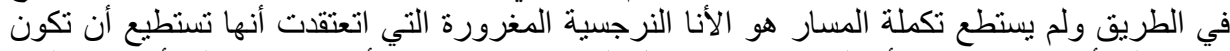

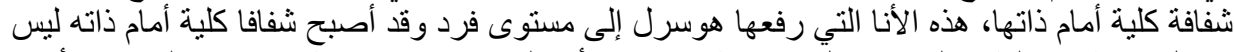

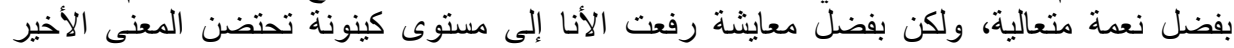

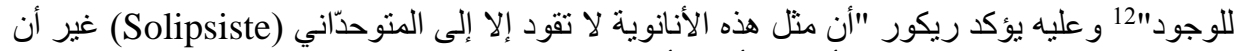

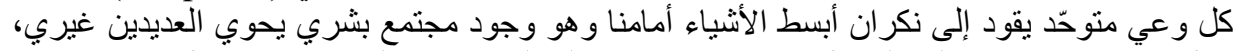

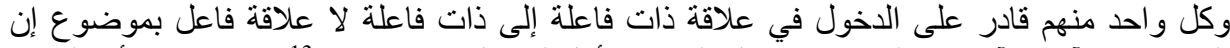

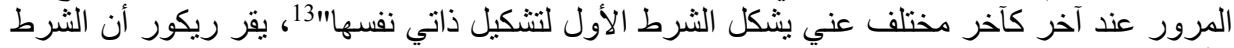
الأول لمعرفة ذاني هو التعرف على ذات التر الآخرين و التحاور معها.

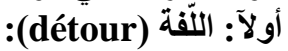

في كتابه الذات عينها كآخر أقرّ"بأن الذات ليست بمفهوم مجرد بل هي ذات ذات منغمسة

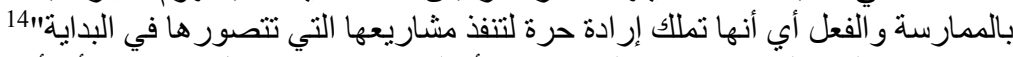

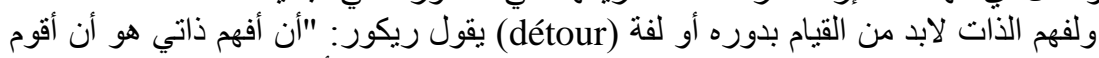

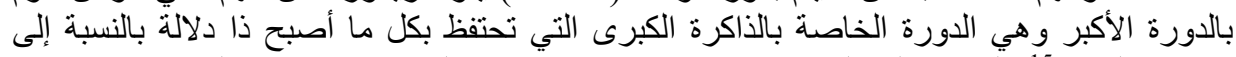

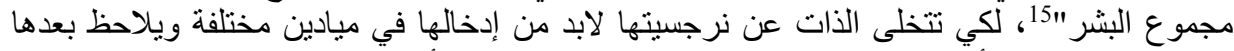

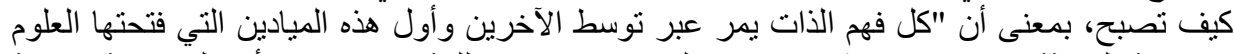

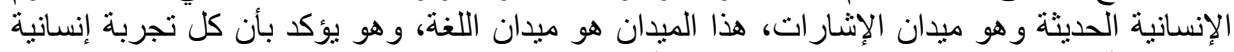

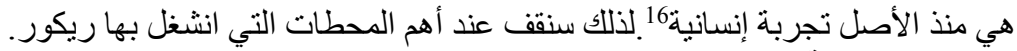

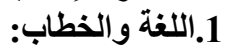

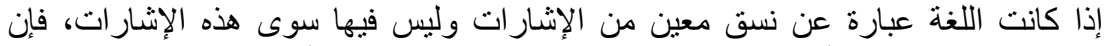

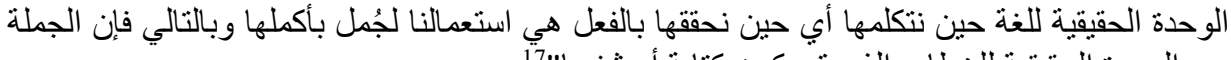

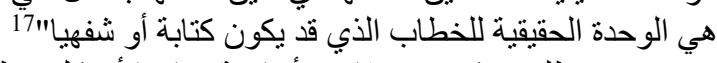

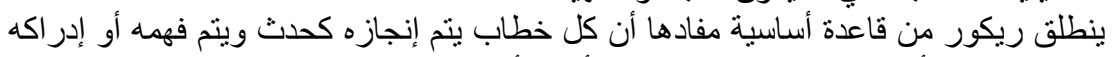

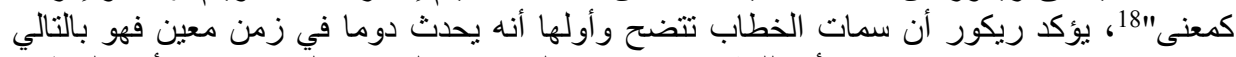

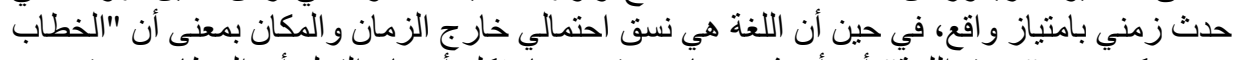

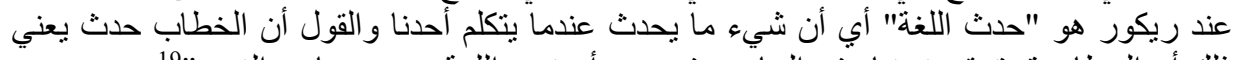
ذلك أن الخطاب قد تحقق زمنيا وفي الحاضر في حين أن نسق اللغة مضمر خارج الزمن ألغرل 


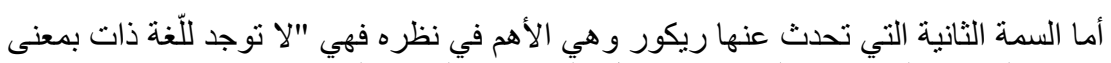

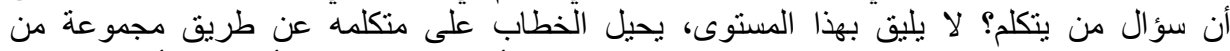

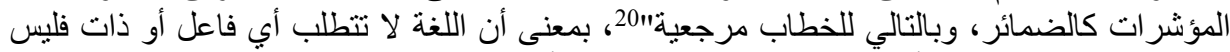

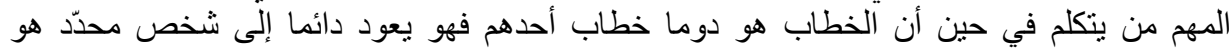

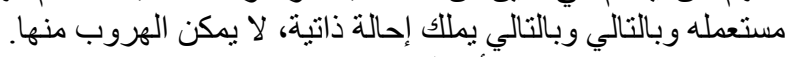

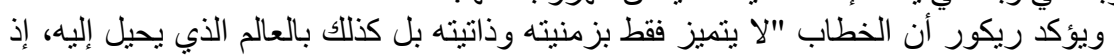

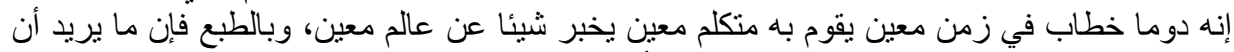

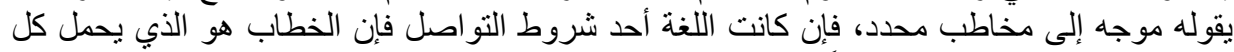

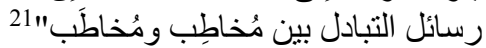

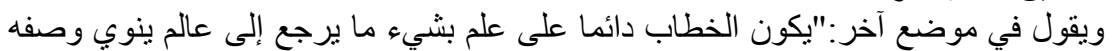

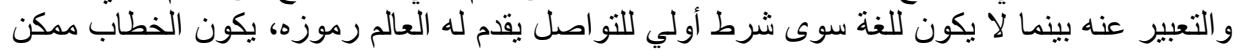

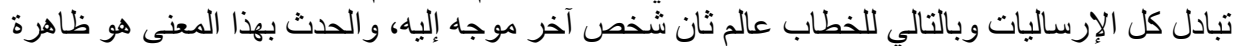

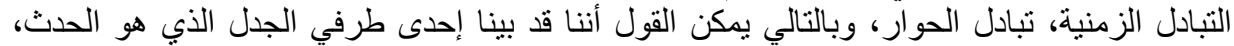

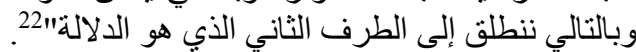

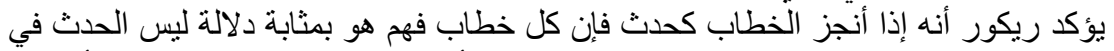

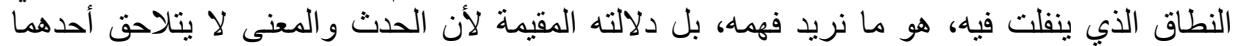

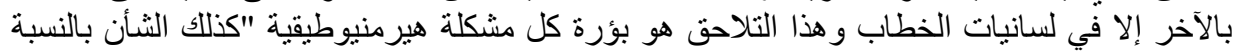

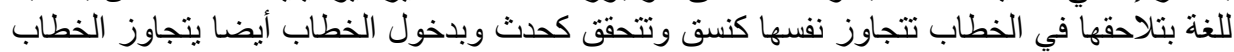

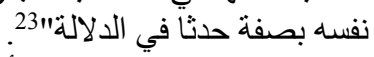

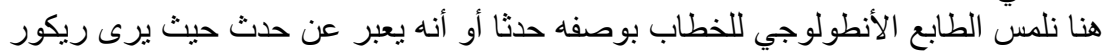

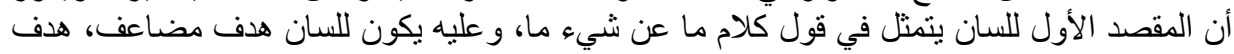

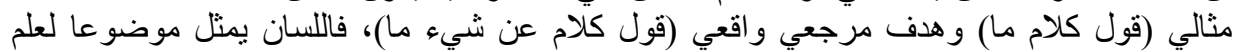

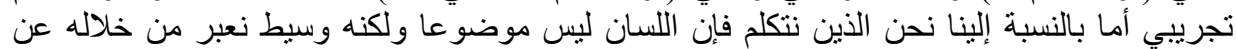
أنفسناو عن الأشياء.

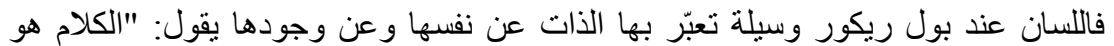

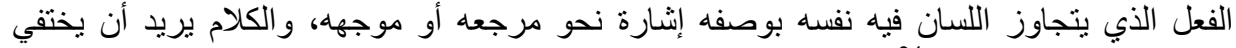

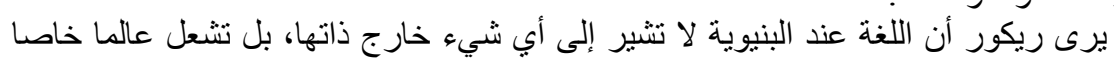

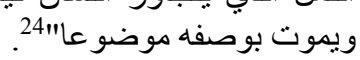

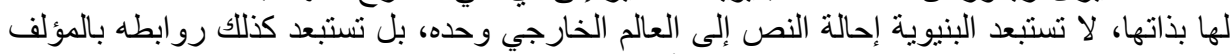

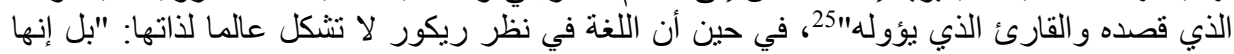

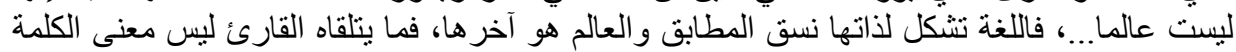

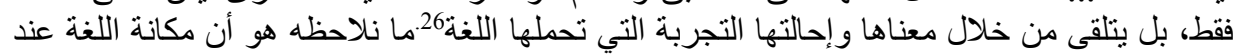

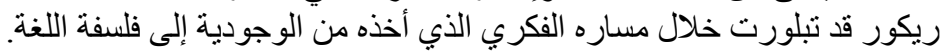
2. دورة ريكور في عالم الرموز: (الاستعارة الحية) الخدية)

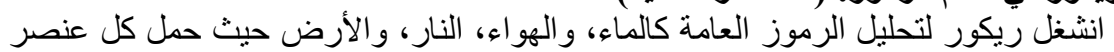

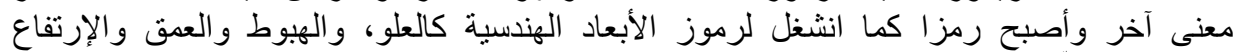

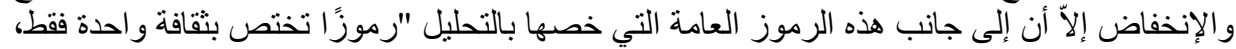

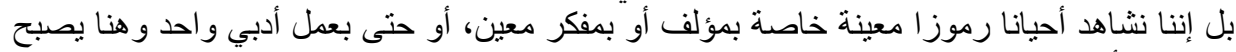

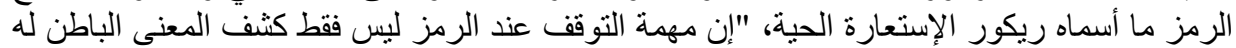
بل محاولة اكتثاف العالم الذي يحيلنا إليه بعد أن نكون قد كثفنا عن كل القوى الخفية التي كانت تستتر لئر لئر 


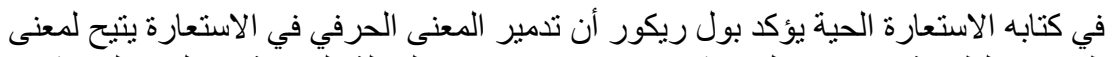

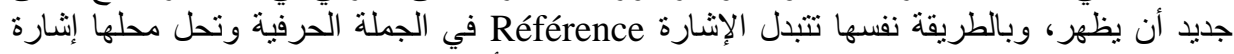

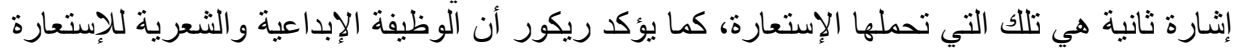

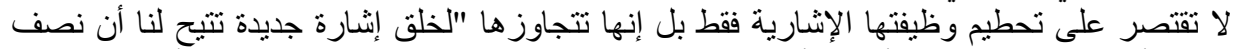

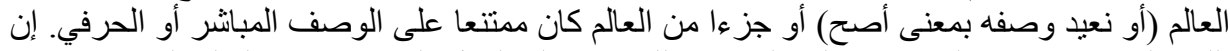

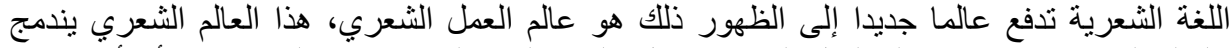

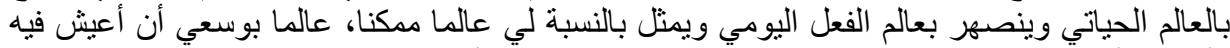

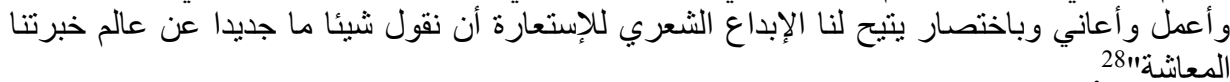

3.دورة ريكور حول النص:يؤكد ريكور أن الخطاب حين يكتب يصبح "نصا مؤلفا من جمل عدة أب إي

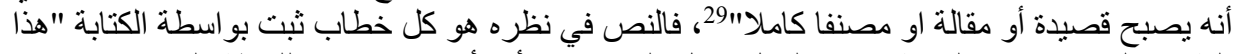

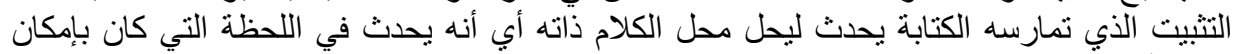

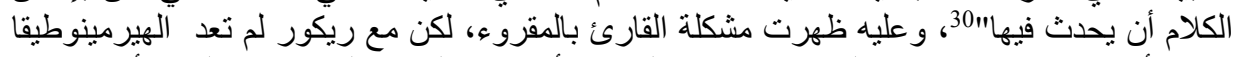

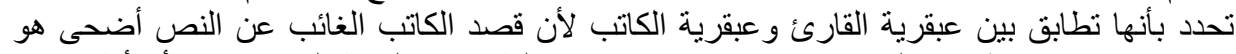

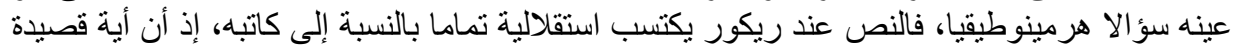

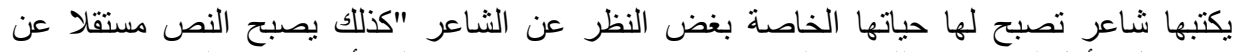

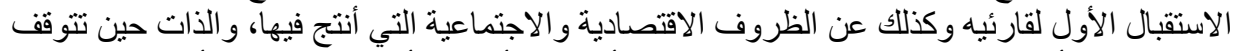

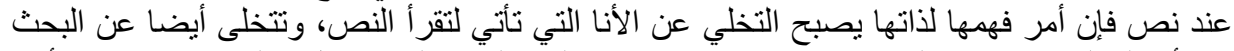

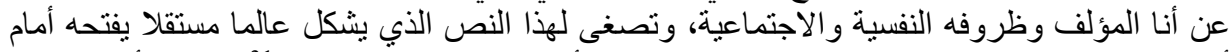

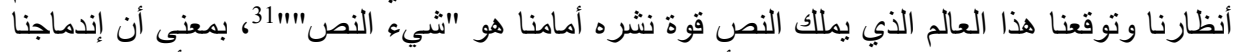

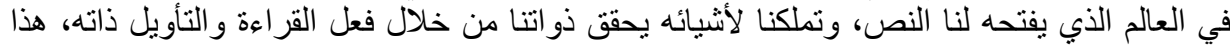

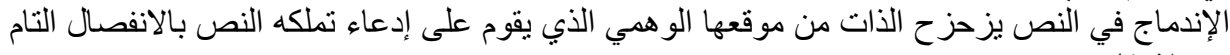

يرى ريكور أن النص هو الآخر الذي يقودني على ذاتي ما اخترت أن أنخرط في حبكته

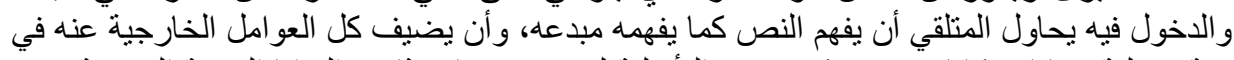

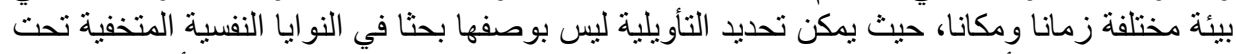

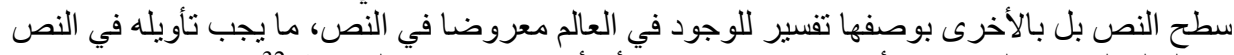

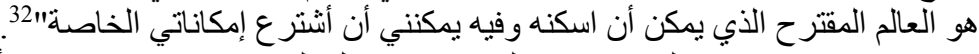

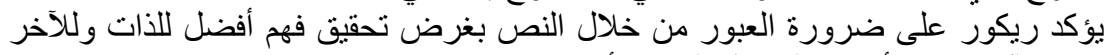

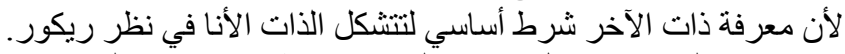

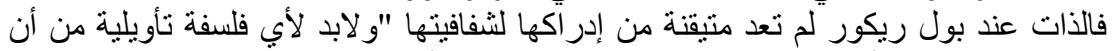

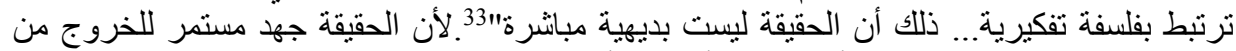

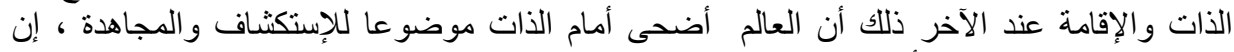

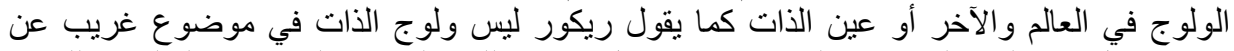

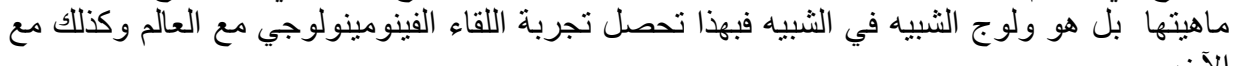

ثانيا: التماسف (Distanciation):

هذا المصطلح التماسف يعده ريكور مصطلحا شخصيا ساهم به في إثر اء القاموس الفلسفي فما 
أيقن ريكور كما سبق الذكر أن الفينومينولوجيا التي طبقها في المجلد الأول من فلسفة الإرادة،

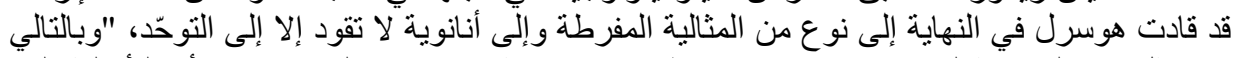

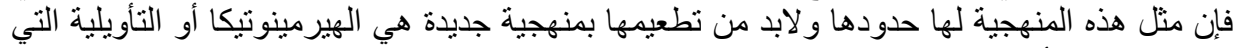

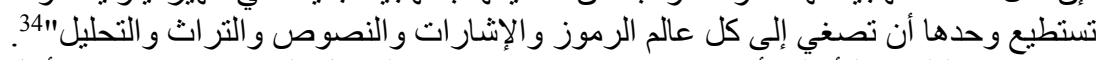

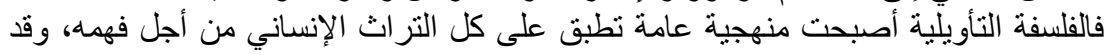

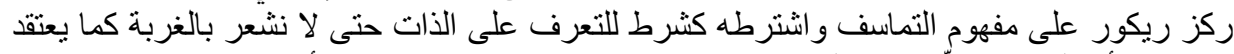

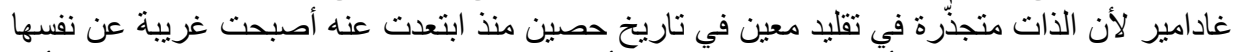

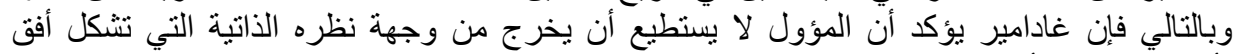

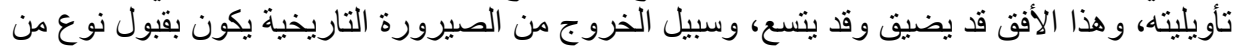

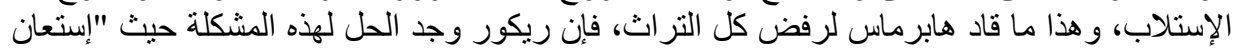

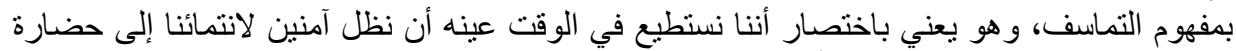

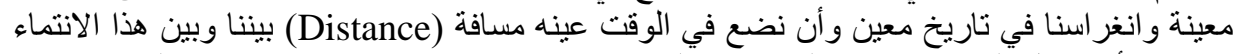

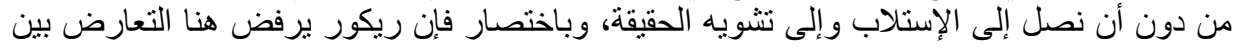

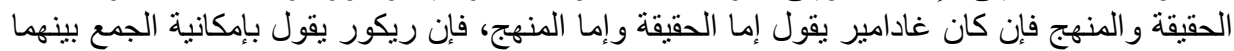

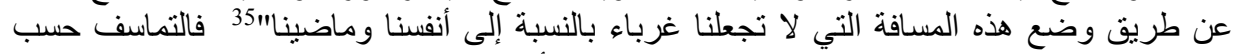

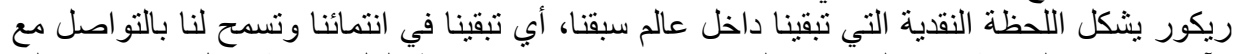

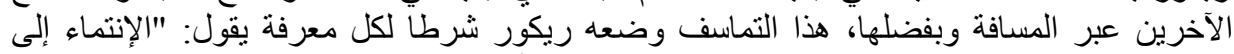

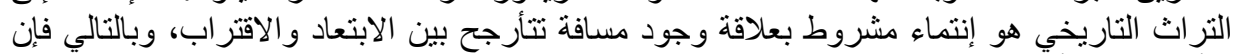

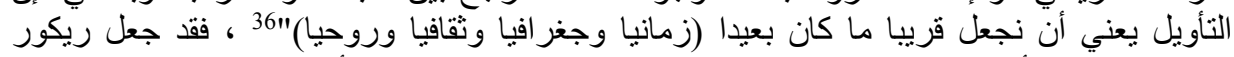

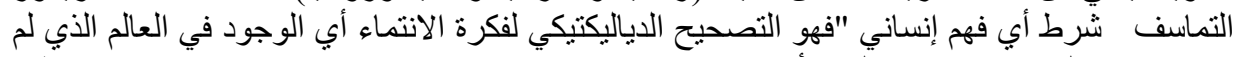

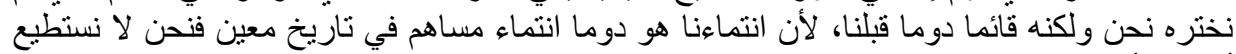

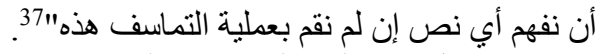

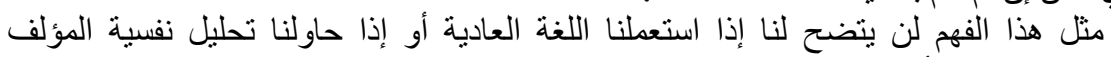

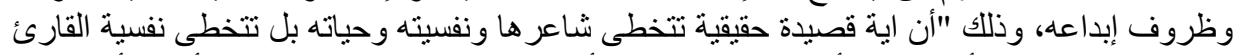

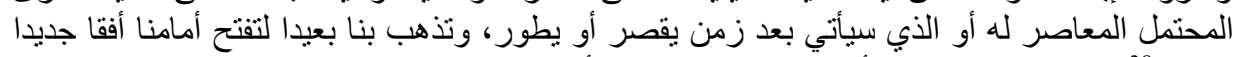

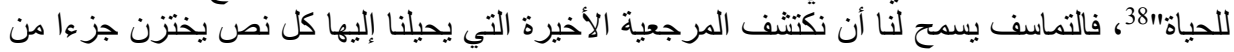

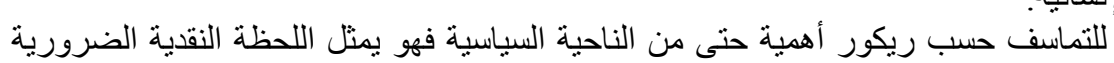
التجربة الإنسانية.

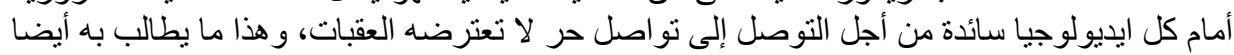

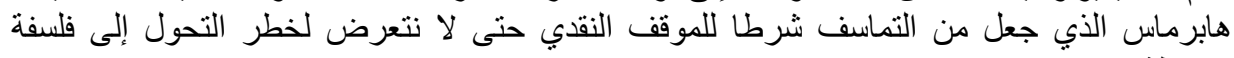
محافظة جديدة

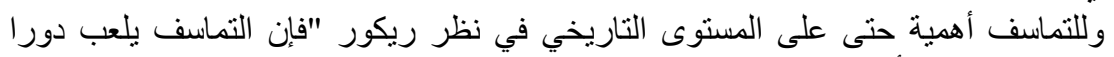

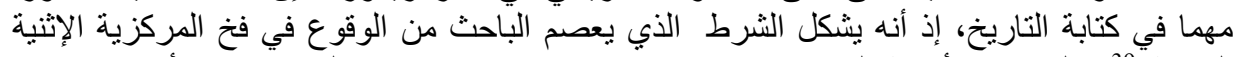

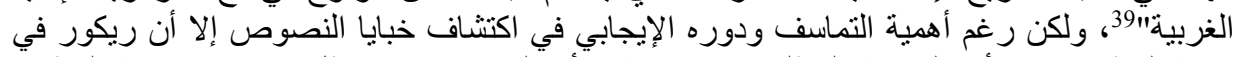

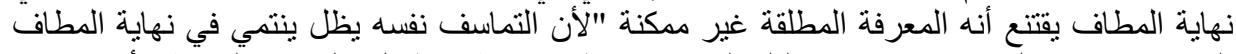

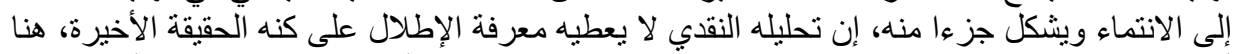

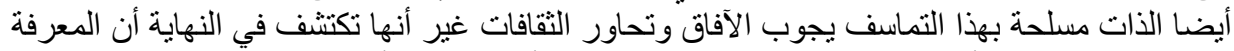

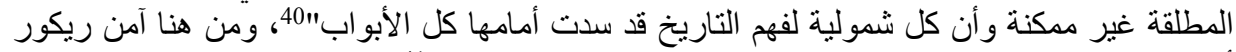

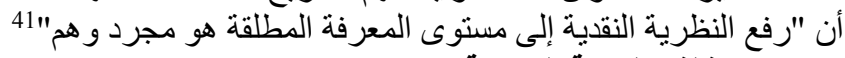

ثالثا: الهوية السردية Identité narrative: 


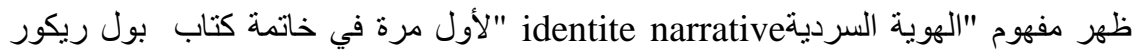

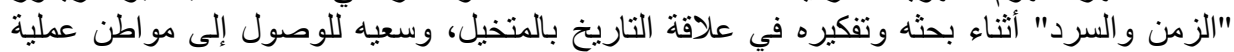

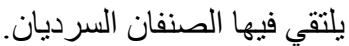

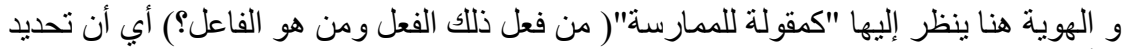

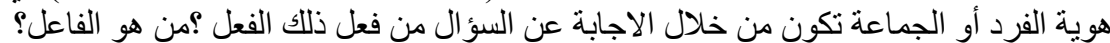

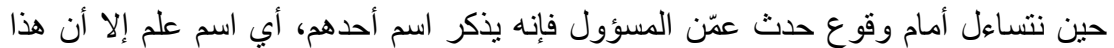

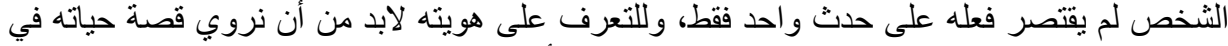

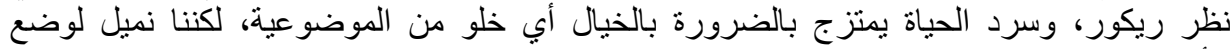
الأحداث في شكل قصة و هذا ما يسميه بول بال ريكور الهوية السردية.

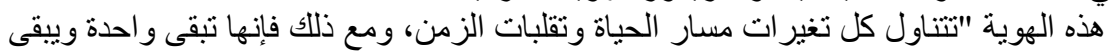

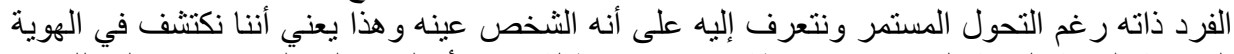

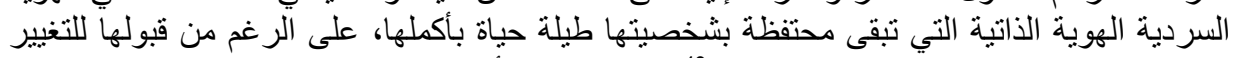

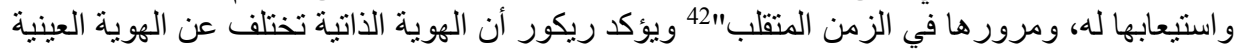

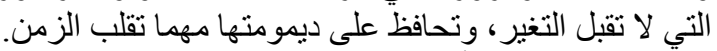

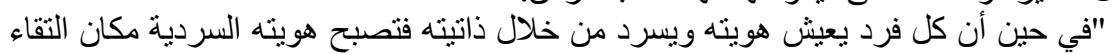

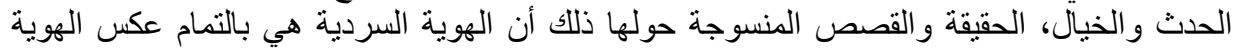

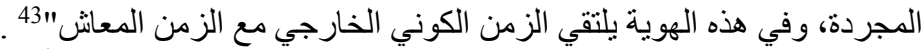

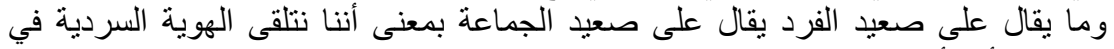

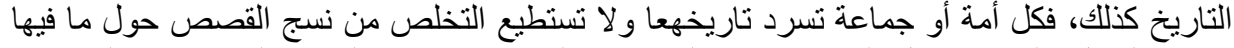

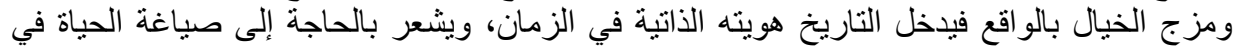

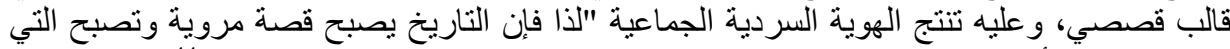

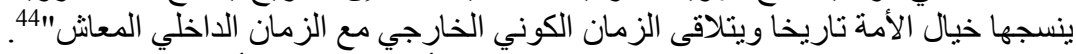

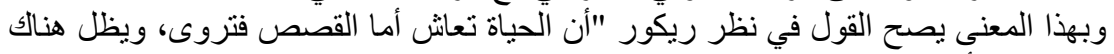

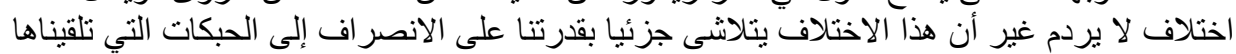

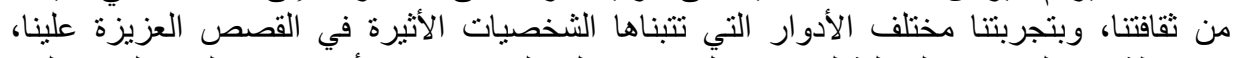

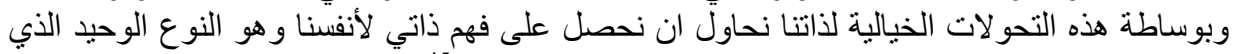
يتهرب من الاختيار الواضح بين التغير الجارف والهوية الهطلقة"45. وبين الاثنين تكمن الهوية السردية

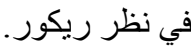

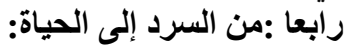

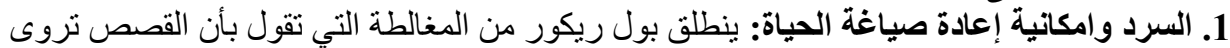

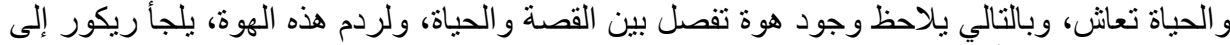
فكرة الخيال ليرى بأية طريقة يعيدنا إلى الحياة.

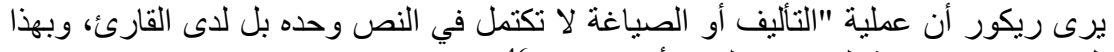

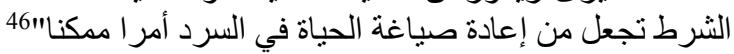

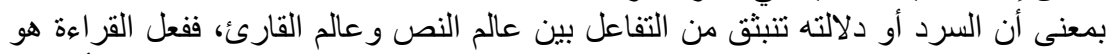

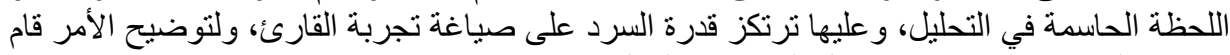

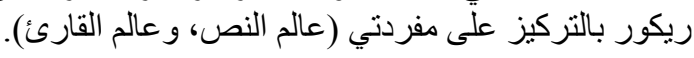




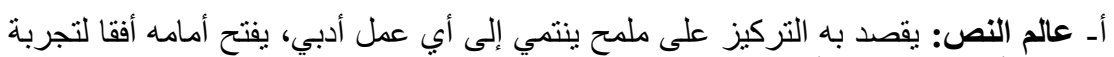

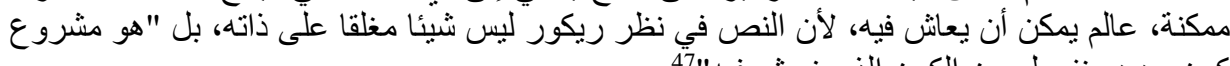

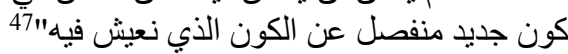

ومن خلال القراءة بمكن نشر أفق عالم ضئه ضمني بحتوي على الأفعال والثخصيات وأحداث

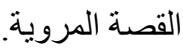

بـ عالم القارئ: ينتمي القارئ إلى أفق تجربة العمل في الخيال، و إلى فعله أو فعلها الو اقعي،

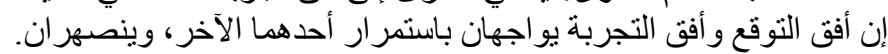

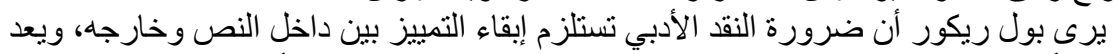

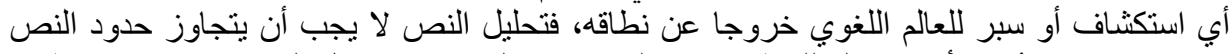

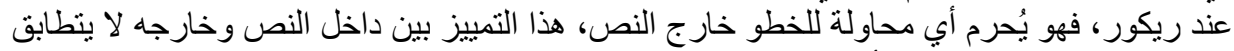

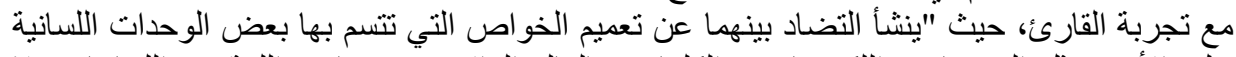

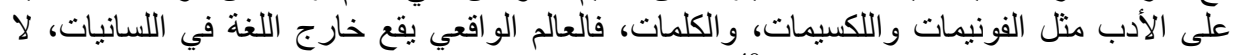

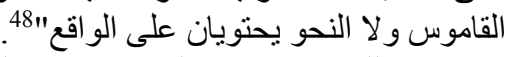

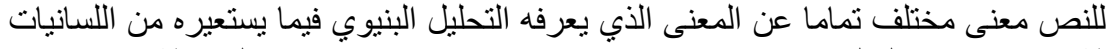

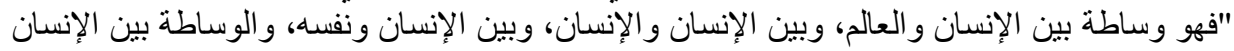

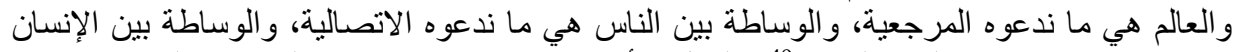

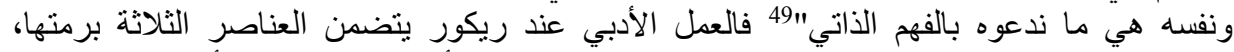

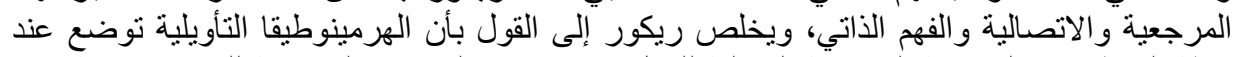

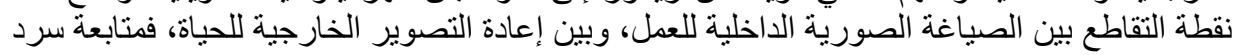

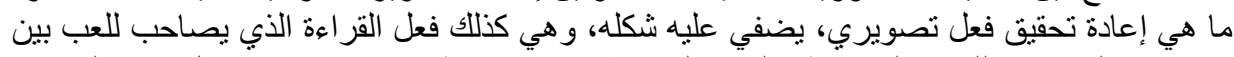

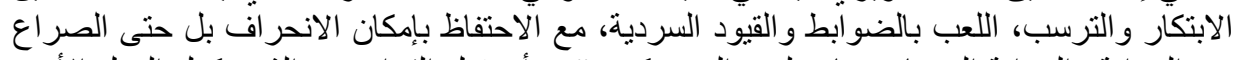

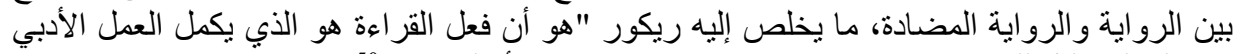

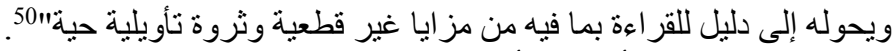

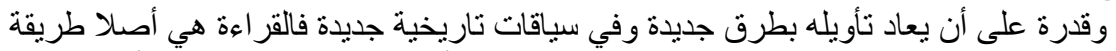

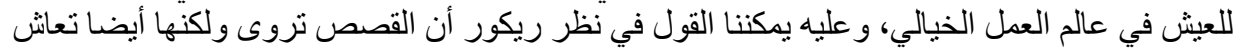

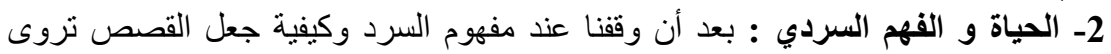

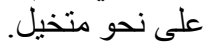

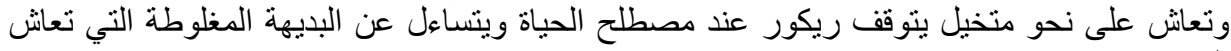

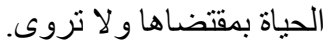

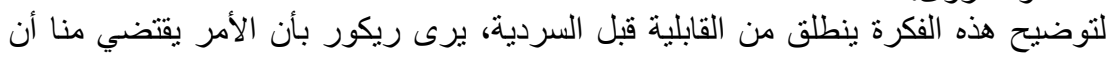

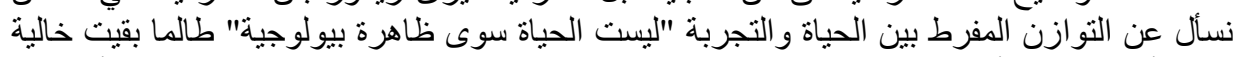

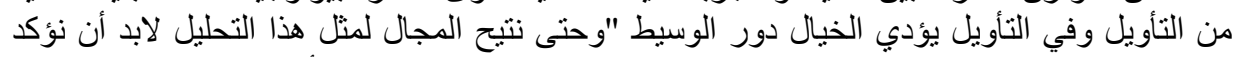

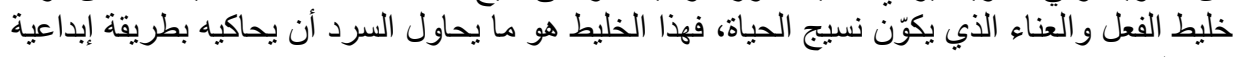
في نظره. - مئر هناك ثناث نقاط يرسو فيها الفهم السردي في نظر بول ريكور نجملها فيما يلي:

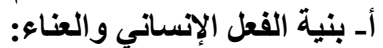

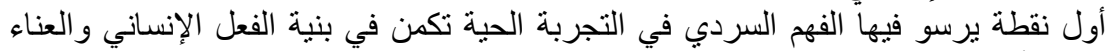

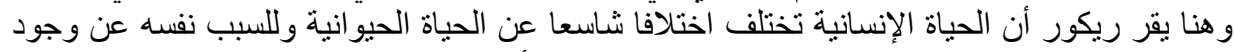

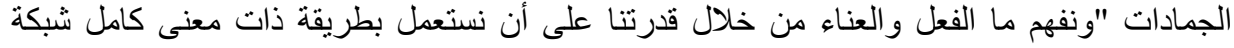

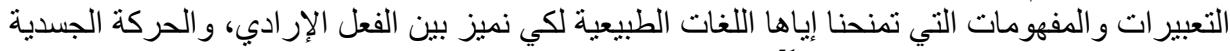
الدحض و السلوك التتريحي النفسي" 


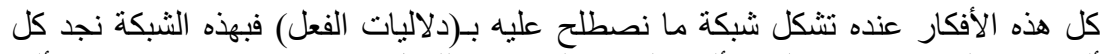

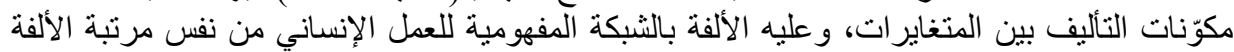

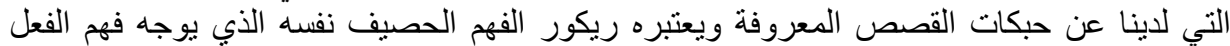

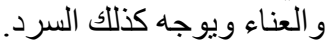
ب - المنابع الرمزية للميدان العملي:

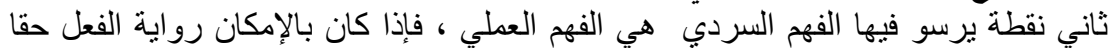

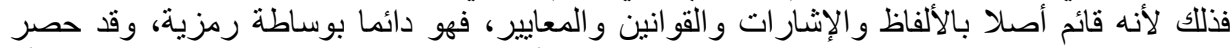
ريكور ملاحظاته فيما يصطلح عليه بالرمزية الضمنية أو الكامنة، في مقابل الرمزية الصنائل الصريحة أو أو

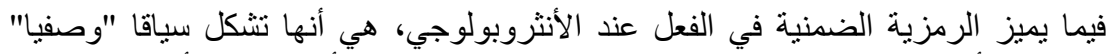

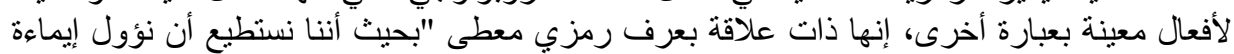

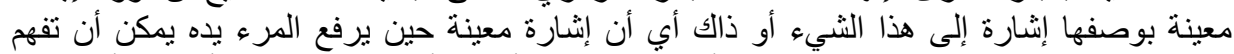

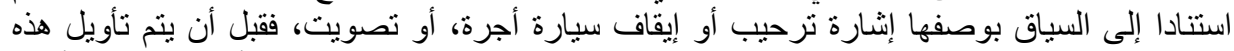

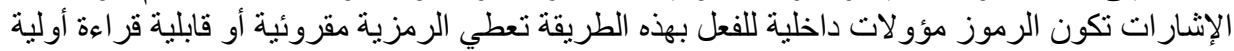

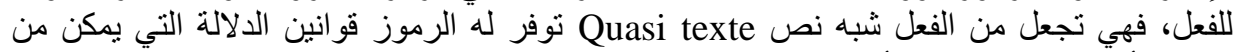

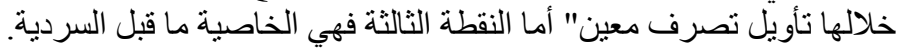

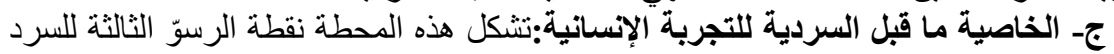

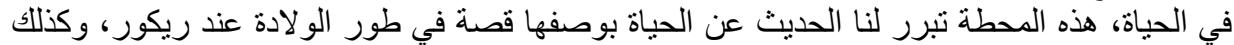

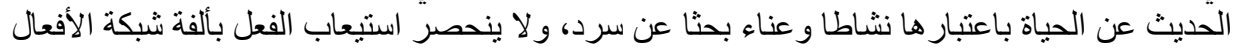

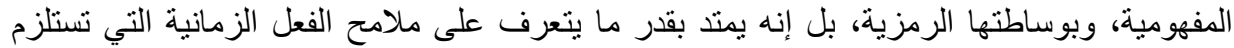

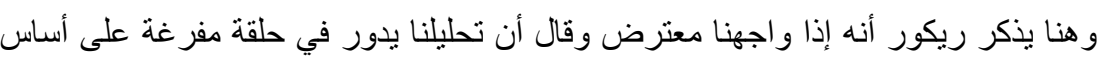

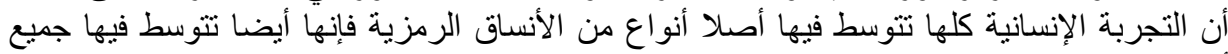

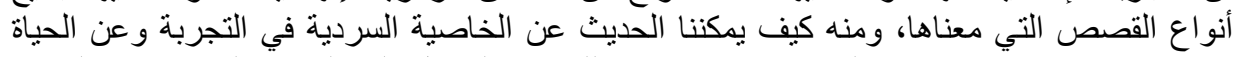

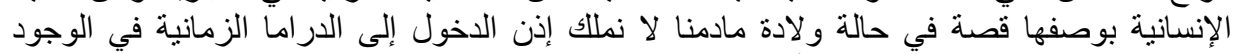

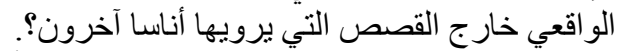

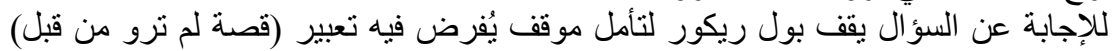

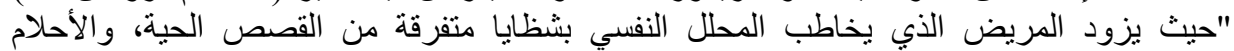

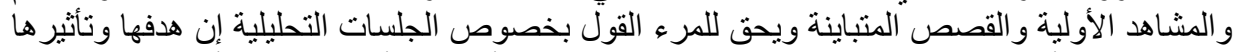

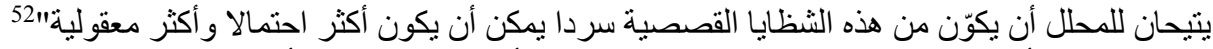

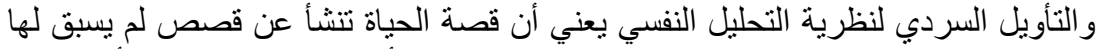

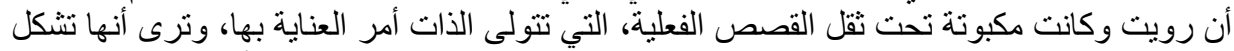

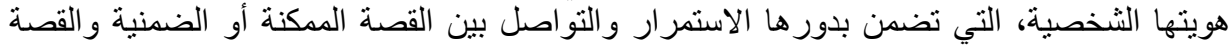
الصريحة أو الفعلية التي تنظاهر بتحمل مسؤوليتها.

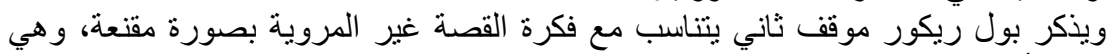

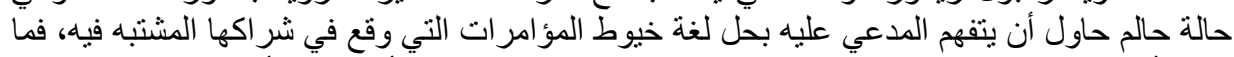

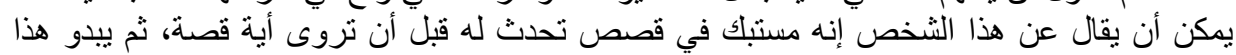

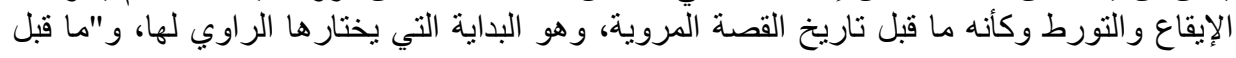


القصة هو ما يربطها بكل أكثر اتساعاويعطيها خلفيتها، وتتكون هذه الخلفية من التراكب الحي للقصص المعيثة جميعا"53.

ويخلص ريكور إلى القول إنّ القصة تجيب على الإنسان والنتيجة الرئيسة لهذا التحليل

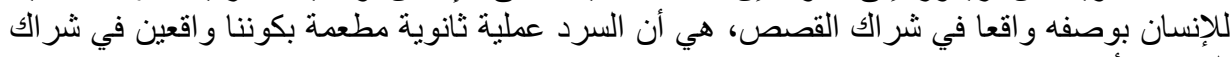
القصص أصلان.

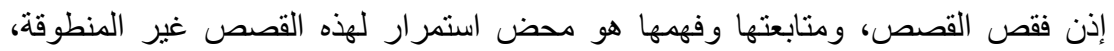

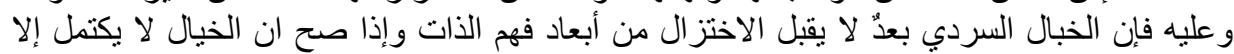

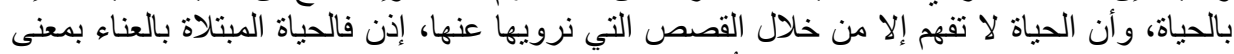

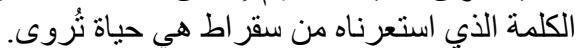

خاتمة

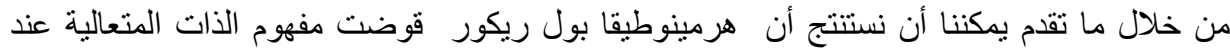

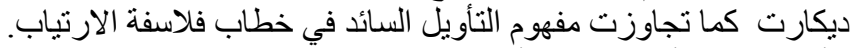

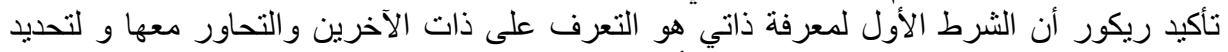

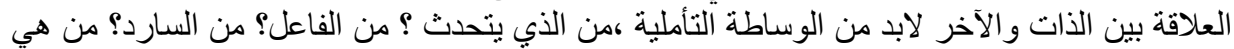

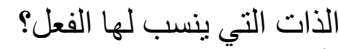
تأويل المفاهيم عنده يكون من خلال التهاب الترحال بين تأويلات متعددة لأن المفهوم يحمل في ثناياه معاني

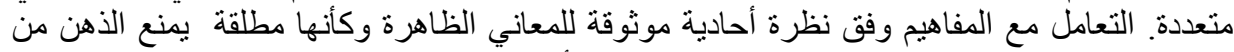

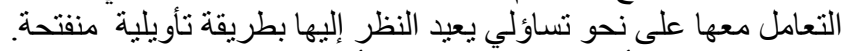

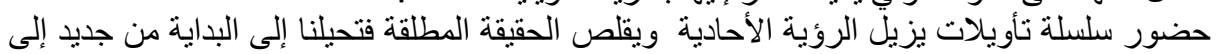

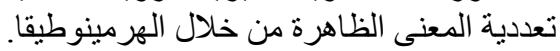

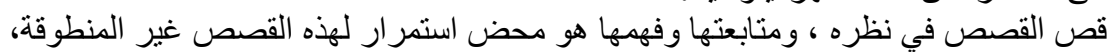

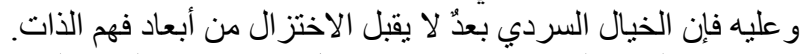

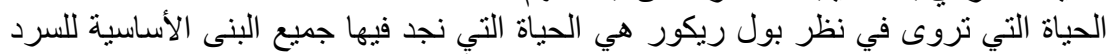

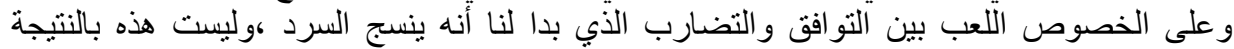

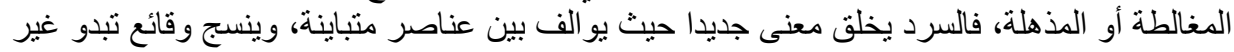

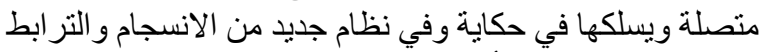
ويستخلص أن حياتتا ستبدو حقلا من الفعالية البنائية المستعارة من الفيلة الفهم السردي، الذي يجعله

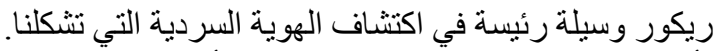

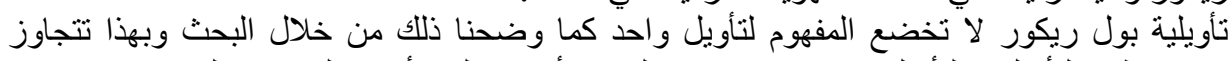

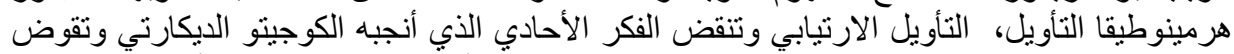

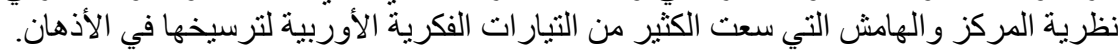

\section{هوامش البحث:}

1. بول ريكور :صر اع التأويلات ، ترجمة منذر عياشي،مر اجعة جورج زيناتي ،دار الكتاب

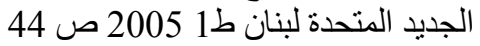

2. محمد شوفي الزين: تأويلات وتفكياتـ فصول في الفكر الغربي المعاصر ـ المركز الثقافي

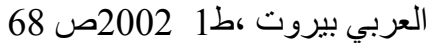
3. ديكارت :تأملات ميتافيزيقية في الفلسفة الأولى ،ترجمة كمال الحاج يوسف،تونس سر اس

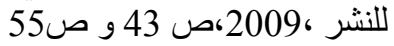

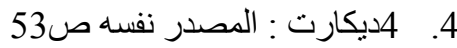


Paul Ricœur: Freud and philosophy translated by Denis Sawage, new $\quad .5$ and London hole university press, 1970, p 32.5Hawen

Ibid, p $33 \quad 6$

$$
\text { 7. }
$$

8. Paul Ricoeur: Freud and Philosophy, P33.

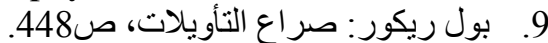

$$
\begin{aligned}
& \text { 10. بول ريكور : من النص إلى الفعل، أبحاث التأويل، ترجمة: محمد بر ادة وحسان بورقيبة، دار }
\end{aligned}
$$

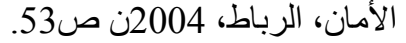

$$
\begin{aligned}
& \text { 11. بول ريكور: الذات عينها كآخر، ترجمة وتقديم جورج زيناتي، مركز دراسات الوحدة }
\end{aligned}
$$

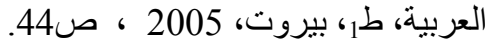

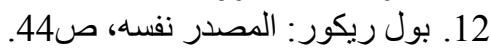

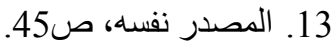

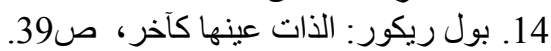

15. Paul Recoeur: Du texte à l'action, essai d'herméneutique, Edition du Seuil , Paris, 1986, P86.

$$
\begin{aligned}
& \text { 16. بول ريكور: الذات عينها كآخر، ص42 }
\end{aligned}
$$

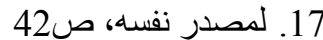

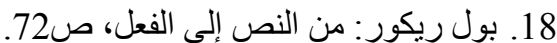

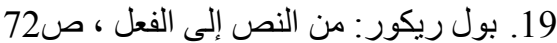

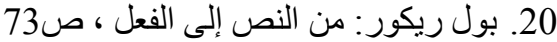

21. Paul Recoeur: Réflexion faite,paris:( Esprit 1995) P184.

$$
\begin{aligned}
& \text { 22 23. بول ريكور : من النص إلى الفعل، ص7474 }
\end{aligned}
$$

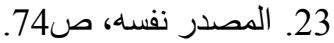

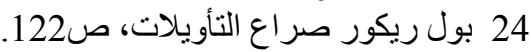

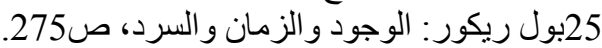

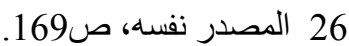

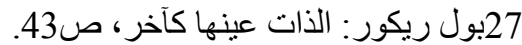

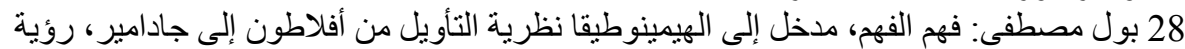

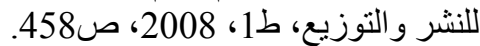

$$
\begin{aligned}
& \text { 29بول ريكور: الذات عينها كآخر ، ص44ونه. }
\end{aligned}
$$

30Paul Recoeur: Du texte a l'action, essai d'herméneutique, P139.

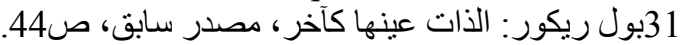

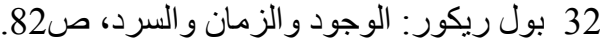

Paul Ricœur: Le confit des interprétations, essai d'herméneutique, Paris, 33 édition du seuil, 1969, p 313

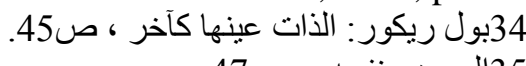

36 Paul Ricoeur: réflexion faite, paris:( Esprit 1995), P51.

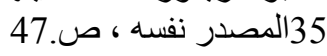

37بول ريكور: الذات عينها كآخر، ص47. 
39Paul Ricœur: temps et Récit, T3, le temps raconté, P64

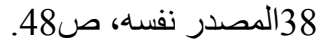

41 Paul Ricœur: du texte a l'action, P330.

40 بول ريكور: الذات عبنها كآخر ، ص49.

42بول ريكور : الذات عينها كآخر ، ص .660

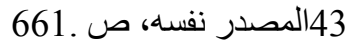

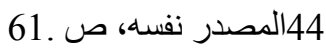

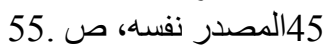

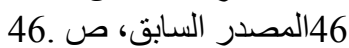

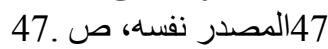

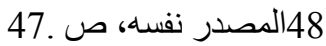

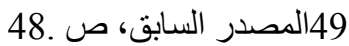

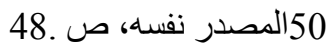

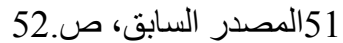

52 ( المصدر السابق، ص.52

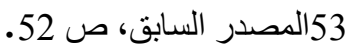

